${ }^{[0000-0003-4043-5300]}$ А. В. Гончаров, к.т.н., доцент, ${ }^{[0000-0002-9296-6827]}$ С. О. Могілей, аспірант

Черкаський державний технологічний університет

б-р Шевченка, 460, Черкаси, 18006, Україна

\title{
РЕАЛІЗАЦІЯ МУЛЬТИМОДАЛЬНИХ ТРАНСПОРТНИХ ЗАДАЧ В РІЗНИХ ПРОГРАМНИХ СЕРЕДОВИЩАХ
}

У статті виконано постановку та реалізацію мультимодальної транспортної задачі за допомогою таких програмних засобів, як MS Excel, Mathcad ma Matlab. Проаналізовано відмінності та особливості алгоритмів реалізачії мультимодальної та класичної транспортних задач в иих середовищах програмування. На основі модельних даних продемонстровано ідентичність результатів, отриманих з використанням різних програмних пакетів.

Ключові слова: мультимодальна транспортна задача, опорний план, критерій оптимізації, ијільова функиія.

Вступ. Класична транспортна задача полягає у відшуканні оптимального плану транспортних перевезень 3 пунктів відправки до пунктів доставки вантажів за критерієм мінімальної собівартості. Якщо в постановці такої задачі врахувати наявність кількох видів транспорту (що функціонують «паралельно»), то таку задачу називають мультимодальною.

Класичні задачі оптимізації, в тому числі транспортні, так само, як і задачі інтермодальних, мультимодальних та змішаних перевезень, $\epsilon$ предметом вивчення багатьох вітчизняних та зарубіжних науковців [1-11]. В їхніх дослідженнях такі задачі розглядаються, насамперед, з точки зору розробки спеціалізованого та вузькопрофільного програмного забезпечення (програмних додатків), які дають змогу автоматизувати процес реалізації відповідної задачі та прийняти оптимальне управлінське рішення.

Розв'язувати класичну транспортну задачу можна за допомогою різних програмних засобів. Так, зокрема, реалізації цієї задачі в програмному середовищі MS Excel присвячено доволі велику кількість сучасних досліджень [12-14]. Основним механізмом реалізації в цьому випадку виступає спеціальна надбудова «Пошук рішення» (англ. Solver), яка дає можливість одразу отримати оптимальний план транспортних перевезень при заданих початкових обмеженнях задачі.

Схожий підхід застосовується і при реалізації класичної транспортної задачі за допомогою Mathcad [15]. В цьому випадку буде використовуватися вбудована функція Mini-

(C) А. В. Гончаров, С. О. Могілей, 2020 DOI: $10.24025 / 2306-4412.3 .2020 .215516$ mize (за аналогією з цільовою функцією собівартості, що мінімізується).

Крім того, ще одним доволі поширеним програмним засобом реалізації задач подібного типу є середовище Matlab. В дослідженні [16] подано лістинги програм, що реалізують класичну транспортну задачу за допомогою найбільш відомих методів. У цій роботі буде використано зведення транспортної задачі до задачі лінійного програмування, а її реалізація проведена за допомогою функції Linprog.

Метою цієї роботи $є$ дослідження можливостей різних програмних середовищ (на прикладі MS Excel, Mathcad та Matlab) реалізовувати саме мультимодальну транспортну задачу за допомогою наявних вбудованих механізмів.

Постановка мультимодальної транспортної задачі. Мультимодальна транспортна задача полягає у відшуканні оптимального плану транспортних перевезень за наявності кількох видів транспорту: наприклад, автомобільного, залізничного та водного. Критерієм оптимізації в рамках цієї транспортної задачі $\epsilon$ найменша сумарна собівартість перевезень вантажів [17].

Математична формалізація цієї задачі $€$ наступною:

$$
S=\sum_{i, j=1}^{m, n} a_{i j} x_{i j}+\sum_{i, j=1}^{m, n} b_{i j} y_{i j}+\sum_{i, j=1}^{m, n} c_{i j} z_{i j} \rightarrow \min ,
$$

де $i=\overline{1, n}, j=\overline{1, m}-n$ пунктів відправки та $m$ пунктів доставки відповідно;

$$
x_{i j}, y_{i j}, z_{i j}-\text { кількість одиниць товару, що }
$$

перевозиться $3 i$-го пункту відправки до $j$-го 
пункту доставки відповідно автомобільним, залізничним та водним транспортом (шукані величини);

$$
a_{i j}, b_{i j}, c_{i j} \text { - вартість перевезення одини- }
$$

ці товару $3 i$-го пункту відправки до $j$-го пункту доставки відповідно автомобільним, залізничним та водним транспортом;

$S$ - функція собівартості.

В загальному випадку ця задача є закритою, оскільки до неї можна звести відкриту задачу, що суттєво не вплине на алгоритм іï розв’ язання. Інакше кажучи, сума потреб пунктів доставки дорівнює сумі запасів у пунктах відправки. Так само можна обмежитися розглядом задачі мінімізації, зважаючи на те, що вона $є$ двоїстою до задачі максимізації.

Таким чином, множина обмежень $D$ задачі складається 3 таких рівнянь та нерівностей:

$$
D:\left\{\begin{array}{l}
\sum_{i, j=1}^{m, n} x_{i j} \leq x ; \sum_{i, j=1}^{m, n} y_{i j} \leq y ; \sum_{i, j=1}^{m, n} z_{i j} \leq z ; \\
\sum_{j=1}^{m} N_{j}=\sum_{i, j=1}^{m, n}\left(x_{i j}+y_{i j}+z_{i j}\right)=\sum_{i=1}^{n} M_{i},
\end{array}\right.
$$

де $\quad x, y, z-$ сумарна вантажопідйомність парків автомобільного, залізничного та водного видів транспорту відповідно;

$M_{i}, N_{j}-$ величини запасів в $i$-му пункті відправки та потреб $j$-го пункту доставки відповідно

Розглянемо реалізацію цієї задачі за допомогою MS Excel, Mathcad та Matlab.

Реалізація поставленої задачі за допомогою MS Excel. Заповнимо таблиці вартостей перевезень (в умовних грошових одиницях) 3 пунктів відправки до пунктів доставки по кожному виду транспорту (таблиці 1-3).

Таблиця 1 - Вартість перевезень автомобільним транспортом (ум. гр. од.)

\begin{tabular}{|c|c|c|}
\hline 23 & 45 & 11 \\
\hline 43 & 12 & 3 \\
\hline 7 & 9 & 65 \\
\hline
\end{tabular}

Таблиця 2 - Вартість перевезень залізничним транспортом (ум. гр. од.)

\begin{tabular}{|c|c|c|}
\hline 21 & 42 & 8 \\
\hline 48 & 10 & 1 \\
\hline 19 & 8 & 37 \\
\hline
\end{tabular}

Таблиця 3 - Вартість перевезень річковим транспортом (ум. гр. од.)

\begin{tabular}{|c|c|c|}
\hline 27 & 39 & 9 \\
\hline 40 & 14 & 2 \\
\hline 13 & 6 & 46 \\
\hline
\end{tabular}

Початкові опорні плани по кожному 3 видів транспорту залишаємо порожніми. Встановимо наступні обмеження за кількістю запасів і потреб пунктів відправки та доставки: $(4200 ; 5300 ; 3700)$ та $(3100 ; 4600 ; 5500)$.
За допомогою надбудови «Пошук рішення», врахувавши обмеження за величинами запасів та потреб, а також умову невід'ємності елементів планів перевезень, отримаємо наступні плани (в умовних одиницях) по кожному виду транспорту (таблиці 4-6).

Таблиця 4 - План перевезень автомобільним транспортом (ум. од.)

\begin{tabular}{|c|c|c|}
\hline 0 & 0 & 0 \\
\hline 0 & 0 & 0 \\
\hline 3100 & 0 & 0 \\
\hline
\end{tabular}

Таблиця 5 - План перевезень залізничним транспортом (ум. од.)

\begin{tabular}{|c|c|c|}
\hline 0 & 0 & 4200 \\
\hline 0 & 4000 & 1300 \\
\hline 0 & 0 & 0 \\
\hline
\end{tabular}


Таблиця 6 - План перевезень річковим транспортом (ум. од.)

\begin{tabular}{|c|c|c|}
\hline 0 & 0 & 0 \\
\hline 0 & 0 & 0 \\
\hline 0 & 600 & 0 \\
\hline
\end{tabular}

Водночас загальна собівартість переве- що сумарний план транспортних перевезень зень становитиме 100200 ум. од. Зазначимо, буде наступним (таблиця 7):

Таблиця 7 - Сумарний план перевезень (ум. од.)

\begin{tabular}{|c|c|c|}
\hline 0 & 0 & 4200 \\
\hline 0 & 4000 & 1300 \\
\hline 3100 & 600 & 0 \\
\hline
\end{tabular}

Отже, за допомогою відповідної надбудови функціонал MS Excel дає можливість знайти оптимальні плани транспортних перевезень при реалізації поставленої задачі. Сам алгоритм реалізації мультимодальної транспортної задачі доволі незначно відрізняється від аналогічного алгоритму, що застосову- ється при розв'язанні відповідної класичної задачі.

Реалізація мультимодальної транспортної задачі в середовищі Mathcad. Матриці вартостей перевезень на автомобільному, залізничному та річковому видах транспорту виглядатимуть наступним чином (рисунок 1):

$$
\mathrm{Ca}:=\left(\begin{array}{ccc}
23 & 45 & 11 \\
43 & 12 & 3 \\
7 & 9 & 65
\end{array}\right) \quad \mathrm{Cr}:=\left(\begin{array}{ccc}
21 & 42 & 8 \\
48 & 10 & 1 \\
19 & 8 & 37
\end{array}\right) \quad \quad \mathrm{Cw}:=\left(\begin{array}{ccc}
27 & 39 & 9 \\
40 & 14 & 2 \\
13 & 6 & 46
\end{array}\right)
$$

Рисунок 1 - Матриці вартостей перевезень по кожному виду транспорту

Далі введемо матриці обмежень за ве- відправки і доставки (рисунок 2): личинами запасів та потреб у пунктах

$$
A=\left(\begin{array}{l}
4200 \\
5300 \\
3700
\end{array}\right) \quad B:=\left(\begin{array}{l}
3100 \\
4600 \\
5500
\end{array}\right)
$$

\section{Рисунок 2 - Матриці обмежень запасів та потреб}

Будуємо цільову функцію оптимізації та вводимо початкові (нульові) значення для елементів опорних планів по кожному виду транспорту (рисунок 3):

$$
\begin{aligned}
& f(x, y, z):=\sum_{i=0}^{2} \sum_{j=0}^{2}\left[\left(\mathrm{Ca}_{i, j} \cdot \mathrm{x}_{\mathrm{i}, \mathrm{j}}\right)+\left(\mathrm{Cr}_{\mathrm{i}, \mathrm{j}} \cdot \mathrm{y}_{\mathrm{i}, \mathrm{j}}\right)+\left(\mathrm{Cw}_{\mathrm{i}, \mathrm{j}} \cdot \mathrm{z}_{\mathrm{i}, \mathrm{j}}\right)\right] \\
& \mathrm{x}_{2,2}:=0 \quad \mathrm{y}_{2,2}:=0 \quad \mathrm{z}_{2,2}:=0
\end{aligned}
$$

Рисунок 3 - Цільова функція задачі 
Описуємо блок Given, в якому врахову- також умову невід'ємності елементів опорних ємо обмеження, наведені в матрицях А та В, а планів (рисунок 4):

$$
\begin{array}{l|l|l}
\sum_{j=0}^{2}\left(x_{0, j}+y_{0, j}+z_{0, j}\right)=A_{0} & \sum_{j=0}^{2}\left(x_{1, j}+y_{1, j}+z_{1, j}\right)=A_{1} & \sum_{j=0}^{2}\left(x_{2, j}+y_{2, j}+z_{2, j}\right)=A_{2} \\
\sum_{i=0}^{2}\left(x_{i, 0}+y_{i, 0}+z_{i, 0}\right)=B_{0} & \sum_{i=0}^{2}\left(x_{i, 1}+y_{i, 1}+z_{i, 1}\right)=B_{1} & \sum_{\substack{i=0 \\
x \geq 0 \\
y \geq 0}} \quad \\
& &
\end{array}
$$

Рисунок 4 - Опис обмежень поставленої задачі

За допомогою функції Minimize отри- залізничному та річковому видах транспорту маємо плани перевезень на автомобільному, окремо (рисунок 5).

$$
\begin{array}{cc|}
\mathrm{V}:=\operatorname{Minimize}(\mathrm{f}, \mathrm{x}, \mathrm{y}, \mathrm{z}) & \mathrm{V}=\left(\begin{array}{l}
\{3,3\} \\
\{3,3\} \\
\{3,3\}
\end{array}\right) \\
\mathrm{V}_{0}=\left(\begin{array}{ccc}
0 & 0 & 0 \\
0 & 0 & 0 \\
3.1 \times 10^{3} & 0 & 0
\end{array}\right) & \mathrm{V}_{1}=\left(\begin{array}{ccc}
0 & 0 & 4.2 \times 10^{3} \\
0 & 4 \times 10^{3} & 1.3 \times 10^{3} \\
0 & 0 & 0
\end{array}\right) \quad \mathrm{V}_{2}=\left(\begin{array}{ccc}
0 & 0 & 0 \\
0 & 0 & 0 \\
0 & 600 & 0
\end{array}\right)
\end{array}
$$

Рисунок 5 - Плани перевезень по кожному виду транспорту

Сумарний план перевезень та їх загальна вартість відображені на рисунку 6.

$$
\mathrm{V}_{0}+\mathrm{V}_{1}+\mathrm{V}_{2}=\left(\begin{array}{r|cc}
0 & 0 & 4.2 \times 10^{3} \\
0 & 4 \times 10^{3} & 1.3 \times 10^{3} \\
3.1 \times 10^{3} & 600 & 0
\end{array}\right)
$$

$$
\mathrm{f}\left(\mathrm{v}_{0}, \mathrm{v}_{1}, \mathrm{v}_{2}\right)=1.002 \times 10^{5}
$$

\section{Рисунок 6 - Сумарний план перевезень та мінімальне значення цільової функції}

Таким чином, функціональних можливостей програмного середовища Mathcad виявляється достатньо для повноцінного розв'язання мультимодальної транспортної задачі. 3 другого боку, отримати результат іiі реалізації в явному вигляді не видається можливим через його «багатомірність». Втім, особливої потреби в цьому немає, оскільки значення мають лише розв'язки в розрізі кожного з видів транспорту окремо.

Реалізація мультимодальної транспортної задачі в середовищі Matlab. Розв'язання досліджуваної задачі в цьому середовищі програмування виглядатиме наступним чином (лістинги 1 і 2): 


\section{Мультимодальна транспортна задача (М-файл)}

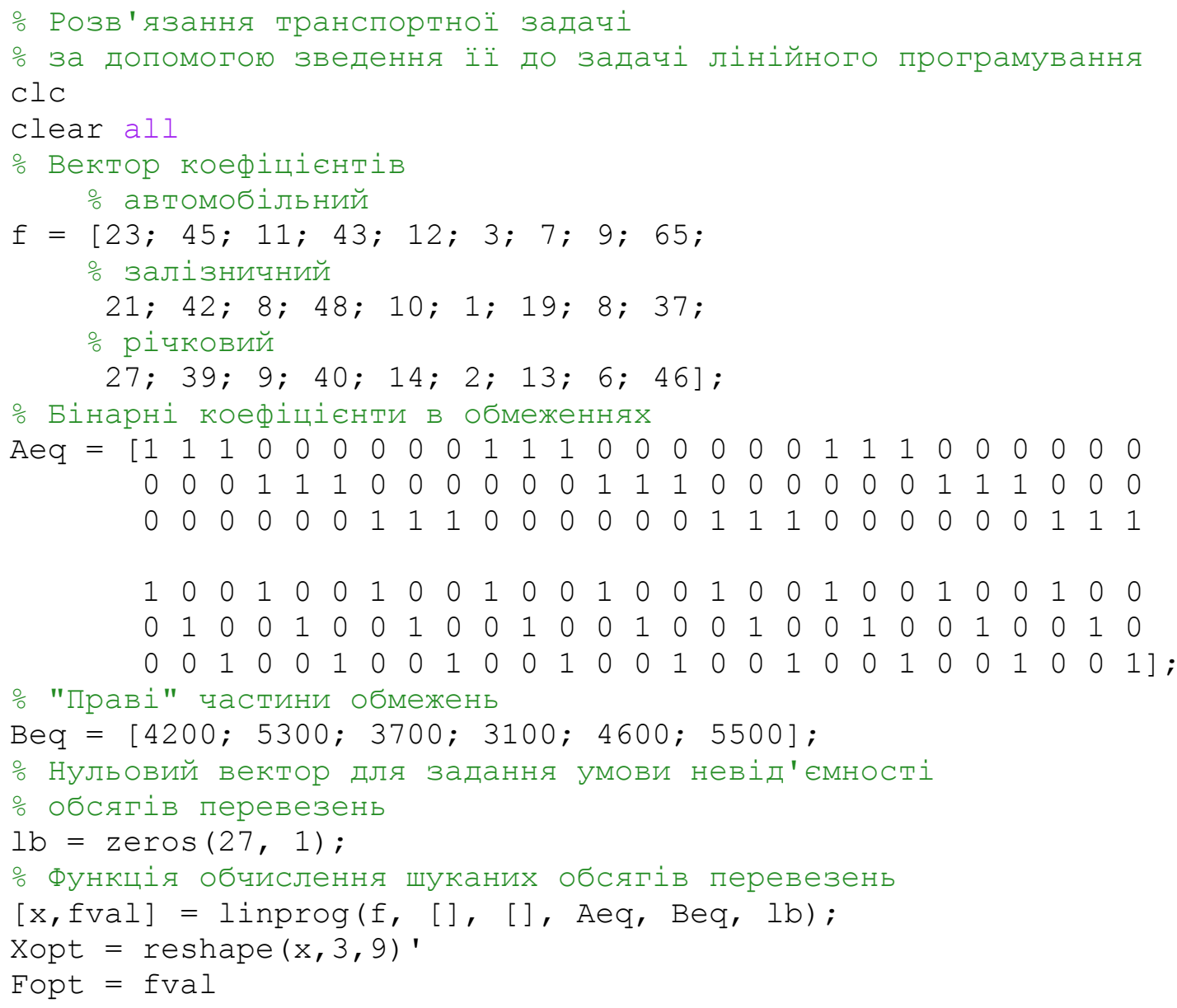

Лістинг 2

Мультимодальна транспортна задача (командне вікно)

Optimal solution found.

Xopt $=$

$\begin{array}{rrr}0 & 0 & 0 \\ 0 & 0 & 0 \\ 3100 & 0 & 0 \\ 0 & 0 & 4200 \\ 0 & 4000 & 1300 \\ 0 & 0 & 0 \\ 0 & 0 & 0 \\ 0 & 0 & 0 \\ 0 & 600 & 0\end{array}$

Fopt $=$

100200 
Основна особливість такого способу реалізації полягає в тому, що матриці розцінок перевезень мають бути подані у вигляді векторів коефіцієнтів, що, в свою чергу, передбачає досить громіздку форму введення початкових даних задачі. На противагу цьому сам процес розв'язання реалізується за допомогою лише однієї вбудованої функції.

Висновки. Досліджено основні підходи до реалізації класичних транспортних задач у таких програмних продуктах, як MS Excel, Mathcad та Matlab. Виконано постановку та реалізацію мультимодальної транспортної задачі в межах функціоналу відповідного програмного забезпечення.

В ході реалізації поставленої задачі в наведених програмних середовищах на основі модельних даних було продемонстровано ідентичність отриманих результатів. Ці результати вказують на можливість розширення постановки задачі, а саме: врахування більшої кількості засобів доставки вантажу, збільшення розмірності задачі - тобто кількості пунктів відправки та доставки, переходу до аналогічних задач з багатьма критеріями оптимізації тощо.

Що стосується проблеми вибору найбільш оптимального програмного забезпечення для розв'язання мультимодальних транспортних задач, то на поточному етапі дослідження важко знайти вагомі аргументи на користь тієї чи іншої програми (з розглянутих вище). Очевидно, що при реалізації подібних задач $з$ великими масивами даних вкрай важливим буде критерій швидкодії алгоритму цієї реалізації. Таким чином, варто буде використати програмне забезпечення 3 «відкритим» кодом - на відміну від вбудованих функцій, це дасть можливість провести більш глибинний аналіз ефективності різних (чисельних) методів розв'язання мультимодальних транспортних задач.

\section{Список використаних джерел}

[1] В. І. Пасічник, Ю. С. Грисюк, та О. В. Пацьора, "Ефективність інтермодальних перевезень як елемент забезпечення високої якості транспортних послуг", Управління проектами, системний аналіз і логістика. Технічна серія, вип. 12, c. 125-131, 2013.

[2] Р. С. Щербина, "Методологічний аспект основних елементів змішаних перевезень експортних вантажів", Збірник наукових праць ДЕТУТ. Серія: Транспортні системи та технологіï, вип. 26-27, с. 242249, 2015.

[3] C. C. Lin, and S. W. Lin, "Two-stage approach to the intermodal terminal location problem", Computers and Operations Research, vol.67, pp. 113-119, 2016. doi: https://doi.org/10.1016/j.cor.2015.09.009.

[4] M. Slavova-Nocheva, "Competitiveness of the transport market in Bulgaria", Ikonomicheski Izsledvania, vol. 21 (3), 2012.

[5] В. В. Сторожев, "Оптимізація параметрів транспортних засобів в мультимодальних системах доставки вантажів", автореф. дис. канд. техн. наук, Одес. нац. морський ун-т, Одеса, 2008.

[6] H. Ayed, C. Galvez-Fernandez, Z. Habbas, and D. Khadraoui, "Solving time-dependent multimodal transport problems using a transfer graph model", Computers and Industrial Engineering, vol. 61, pp. 391-401, 2011. doi: 10.1016/j.cie.2010.05.018.

[7] H. Ayed, Z. Habbas, D. Khadraoui, and C. Galvez-Fernandez, "A parallel algorithm for solving time dependent multimodal transport problem", in Proc. IEEE Conf. on Intelligent Transportation Systems (ITSC), 2011, pp. 722-727. doi: 10.1109/ ITSC.2011.6082973.

[8] J. E. Flórez, Á. Torralba, J. García, C. Linares López, Á. García-Olaya, and D. Borrajo, "TIMIPLAN: An application to solve multimodal transportation problems", in Scheduling and Planning Applications Workshop (SPARK), 2010.

[9] R. Zelenika, D. Sever, S. Zebec, and B. Pirš, "Logistic operator - fundamental factor in rational production of services in multimodal transport", Promet - Traffic - Traffico, 2005.

[10] D. Elias, B. Nadler, F. Nadler, and G. Hauger, "OPTIHUBS - multimodal hub process optimization by means of micro simulation", Transportation Research Procedia, 2016.2 doi: 10.1016/ j.trpro.2016.05.098.

[11] J. García, J. E. Florez, Á. Torralba, D. Borrajo, C. L. López, Á. García-Olaya, and J. Sáenz, "Combining linear programming and automated planning to solve intermodal transportation problems", European Journal of Operational Research, vol. 227, pp. 216-226, 2013. 
[12] L. Chandrakantha, "Using excel solver in optimization problems", John Jay College of Criminal Justice of CUNY, 2014, pp. 42-49.

[13] O. Ezeokwelume, "Solving linear programming problems and transportation problems using excel solver", International Journal of Scientific \& Engineering Research, vol. 7, iss. 9, pp. 134-142, 2016.

[14] B. Vats, and A. KumarSingh, "Solving transportation problem using excel solver for an optimal solution", MIT International Journal of Mechanical Engineering, vol. 6, no. 1, pp. 18-20, 2016.

[15] V. Ovcharuk, N. Vovkodav, T. Kryvets, and I. Ovcharuk, "Linear programming in Mathcad on the example of solving the transportation problem", Scientific Works of NUFT, vol. 21, iss. 4, pp. 110-117, 2015.

[16] J. Sengamalaselvi, "Solving transportation problem by using Matlab", International Journal of Engineering Sciences \& Research Technology, no. 6 (1), pp. 374-381, 2017. doi: 10.5281/zenodo.259588.

[17] С. В. Заболотній, та С. О. Могілей, "Оптимізація методу побудови опорних планів мультимодальної транспортної задачі", Технологічний аудит та резерви виробництва, № 2 (45), с. 15-20, 2019. doi: https://doi.org/10.15587/2312-

8372.2019.154561

\section{References}

[1] V. I. Pasichnyk, Yu. S. Grysyuk, and O. V. Patsyora, "Efficiency of intermodal transport as an element of ensuring high quality of transport services", Upravlinnja proektamy, systemnyj analiz $i$ logistyka. Tehnichna serija, iss. 12, pp. 125-131, 2013. [in Ukrainian].

[2] R. S. Shherbyna, "Methodological aspect of the main elements of mixed transportation of export cargo", Zbirnyk naukovyh prac' DETUT. Serija: Transportni systemy ta tehnologii', iss. 26-27, pp. 242-249, 2015. [in Ukrainian].

[3] C. C. Lin, and S. W. Lin, "Two-stage approach to the intermodal terminal location problem", Computers and Operations Research, vol. 67, pp. 113-119, 2016. doi: https://doi.org/10.1016/j.cor.2015.09.009.

[4] M. Slavova-Nocheva, "Competitiveness of the transport market in Bulgaria", Ikonomicheski Izsledvania, vol. 21 (3), 2012.

(C) А. В. Гончаров, С. О. Могілей, 2020

DOI: $10.24025 / 2306-4412.3 .2020 .215516$
[5] V. V. Storozhev, "Optimization of vehicle parameters in multimodal cargo delivery systems", Ph.D. thesis, Odessa Nat. Marine Univ., Odessa, 2008. [in Ukrainian].

[6] H. Ayed, C. Galvez-Fernandez, Z. Habbas, and D. Khadraoui, "Solving time-dependent multimodal transport problems using a transfer graph model", Computers and Industrial Engineering, vol. 61, pp. 391-401, 2011. doi: 10.1016/j.cie.2010.05.018.

[7] H. Ayed, Z. Habbas, D. Khadraoui, and C. Galvez-Fernandez, "A parallel algorithm for solving time dependent multimodal transport problem", in Proc. IEEE Conf. on Intelligent Transportation Systems (ITSC), 2011, pp. 722-727. doi: 10.1109/ ITSC.2011.6082973.

[8] J. E. Flórez, Á. Torralba, J. García, C. Linares López, Á. García-Olaya, and D. Borrajo, "TIMIPLAN: An application to solve multimodal transportation problems", in Scheduling and Planning Applications Workshop (SPARK), 2010.

[9] R. Zelenika, D. Sever, S. Zebec, and B. Pirš, "Logistic operator - fundamental factor in rational production of services in multimodal transport", Promet-Traffic-Traffico, 2005.

[10] D. Elias, B. Nadler, F. Nadler, and G. Hauger, "OPTIHUBS - multimodal hub process optimization by means of micro simulation", Transportation Research Procedia, 2016. doi: 10.1016/ j.trpro.2016.05.098.

[11] J. García, J. E. Florez, Á. Torralba, D. Borrajo, C. L. López, Á. García-Olaya, and J. Sáenz, "Combining linear programming and automated planning to solve intermodal transportation problems", European Journal of Operational Research, vol. 227, pp. 216-226, 2013.

[12] L. Chandrakantha, "Using excel solver in optimization problems", John Jay College of Criminal Justice of CUNY, 2014, pp. 42-49.

[13] O. Ezeokwelume, "Solving linear programming problems and transportation problems using excel solver", International Journal of Scientific \& Engineering Research, vol. 7, iss. 9, pp. 134-142, 2016.

[14] B. Vats, and A. KumarSingh, "Solving transportation problem using excel solver for an optimal solution", MIT International Journal of Mechanical Engineering, vol. 6, no. 1, pp. 18-20, 2016.

[15] V. Ovcharuk, N. Vovkodav, T. Kryvets, and I. Ovcharuk, "Linear programming in 
Mathcad on the example of solving the transportation problem", Scientific Works of NUFT, vol. 21, iss. 4, pp. 110-117, 2015.

[16] J. Sengamalaselvi, "Solving transportation problem by using Matlab", International Journal of Engineering Sciences \& Research Technology, no. 6 (1), pp. 374-381, 2017. doi: 10.5281/zenodo. 259588 .
[17] S. V. Zabolotnii, and S. O. Mogilei, "Optimization of the method of constructing reference plans of multimodal transport problem", Tekhnolohichnyi audyt ta rezervy vyrobnytstva, no. 2 (45), pp. 15-20, 2019. doi: https://doi.org/10.15587/23128372.2019.154561. [in Ukrainian].

A. V. Honcharov, Ph.D., associate professor,

S. O. Mogilei, Ph.D. student

Cherkasy State Technological University

Shevchenko blvd, 460, Cherkasy, 18006, Ukraine

\section{IMPLEMENTATION OF MULTIMODAL TRANSPORT TASKS IN DIFFERENT SOFTWARE ENVIRONMENTS}

Multimodal problem is the classic transport problem that assumes simultaneous (parallel) application of several means of cargo delivery. It means, the criterion for optimizing a multimodal transportation problem is, as compared with the classic one, the minimal ultimate transportation cost, whereas there are more than one accessible means of cargo delivery. Today's scientific description, both in the Ukrainian and foreign investigations, considers the problems of this type insufficiently, therefore the issue of testing their models and methodologies is quite significant. Apparently, the calculations of these problems appear to be as well complicated, so it is rather correct to employ for it special programming methods.

The article regards the multimodal transport problem presented and realized through different programming means, among them MS Excel, Mathcad and Matlab. The transportation means are presented as equal to three, since we regard the automobile, the railroad and the river deliveries. The problem requires, for various programming performances, the standard (built-in) functions and methods like Solver for MS Excel, Minimize for Mathcad (as well as Given block) and Linprog for Matlab (using a multimodal transport problem modified into a linear programming problem).

The research has resulted in the analysis of peculiar algorithms for multimodal and classic transport problems, the above mentioned programming methods. Also, the model data has demonstrated identical results obtained through the application of various programming means. The obtained algorithms for solving the multimodal transport problem can be expanded for a larger, than three, number of means for transport delivery.

In perspective, the research holds to solve the multicriteria, at least, two-criteria, multimodal transport problem that would assume more than one criterion of optimization. One of these would be minimizing the level of risks in transportation logistics. function.

Keywords: multimodal transport problem, reference plan, optimization criterion, objective

Стаття надійшла 03.09.2020

Прийнято 10.10.2020 